\title{
A CONSTRUÇÃO E O PAPEL DO PROCESSO DE PROJETO ARQUITETÔNICO
}

\section{BUILDING CONSTRUCTION AND THE ROLE OF THE DESIGN PROCESS IN ARCHITECTURE}

\author{
Daniel de Carvalho Moreira 1 \\ Universidade Estadual de Campinas, \\ Faculdade de Engenharia Civil, \\ Arquitetura e Urbanismo, Campinas - SP \\ Editor Chefe \\ damore@fec.unicamp.br \\ Regina C. Ruschel ${ }^{2}$ \\ Universidade Estadual de Campinas, \\ Faculdade de Engenharia Civil, \\ Arquitetura e Urbanismo, Campinas - SP \\ Editor Chefe \\ parc@fec.unicamp.br
}

\section{Editorial}

A figura do arquiteto como conhecemos hoje tem sua origem no século XV, tanto no campo profissional como o responsável pela concepção do edifício como no campo teórico com as publicações impressas dos primeiros tratados de arquitetura. Estas duas transformações são contemporâneas do surgimento de um outro profissional: o engenheiro. A retomada de elementos clássicos gregos e romanos na arquitetura italiana, que aconteceu a partir dos anos quatrocentos, simplificou algumas questões estruturais mais complexas enfrentadas pelos construtores medievais, como o retorno do arco pleno ou da cobertura plana em substituição aos arcos quebrados ogivais e as cúpulas e abóbadas de berço. Não que questões estruturais complexas fossem evitadas - como demonstra o fantástico engenho do primeiro arquiteto renascentista, Fillipo Bruneleschi, na construção da cúpula da Catedral de Santa Maria del Fiori (MAINSTONE, 1969) - mas a aplicação dos elementos clássicos romanos marcou significativamente o desenvolvimento inicial da profissão do arquiteto. Prova disso é a origem da teoria da arquitetura renascentista estar associada ao impacto do texto de um construtor-arquiteto romano do século I d.C, Vitruvius. O tratado de Vitruvius difundiu-se de modo significativo no início do século XV com a descoberta de um manuscrito bastante completo em Saint-Gall, na Suiça, em 1414, e em 1486 teve uma primeira edição impressa. O texto rapidamente se espalhou pela Itália e influenciou Alberti na organização do seu próprio tratado, o "De re aedificatoria", impresso um ano antes do próprio tratado de Vitruvius, em 1485 (HEARN, 2006). A circulação das versões impressas dos tratados de arquitetura não representava apenas a ampla disseminação da teoria da arquitetura, mas a possibilidade de associar imagens aos conceitos expressos no texto. O impacto destas publicações no campo da arquitetura foi enorme, como sugere Bill Addis ao afirmar que o "livro impresso ilustrado desempenhou um papel essencial no modo como a arquitetura veio a se estabelecer como uma disciplina independente; por essa razão, talvez, os livros dedicados à arquitetura tendiam a dar pouca importância ao papel desempenhado por engenheiros e artesãos na criação de edificações" (ADDIS, 2009, p. 149).

A possibilidade de lidar com questões construtivas complexas - de ordem funcional, estrutural ou formal - e as relações da teoria da arquitetura com outras áreas (BROADBENT, 1982), conforme incorporadas aos propósitos das edificações, foram revertendo gradativamente o quadro de isolamento da

How to cite this article:

MOREIRA, Daniel de Carvalho; RUSCHEL, Regina C.. A construção e o papel do processo de projeto arquitetônico: Editorial. PARC Pesquisa em Arquitetura e Construção, Campinas, v. 6, n. 1, p.1-3, jan./mar. 2015 
arquitetura e estabeleceram um novo contexto de relações entre as disciplinas envolvidas na construção do edifício. $\mathrm{O}$ desenvolvimento da arquitetura e da construção a partir da segunda metade do século XX exigiu que os profissionais comprometidos com o empreendimento de edificar reconsiderassem esses princípios que estão na gênese das profissões do engenheiro e do arquiteto.As novas exigências funcionais, os novos materiais, as novas técnicas construtivas, as novas formações profissionais, as novas tecnologias e os novos processos de projeto - bem como um ritmo acelerado de modificações em todos estes campos - colocaram os envolvidos diante da urgência de uma nova abordagem da construção de edifícios. A variedade dos assuntos relacionados à construção não permite que a habilidade do arquiteto ou do engenheiro opere em isolamento ou tenha que necessariamente se sobressair em relação às outras contribuições. A coexistência de tantos temas é a condição contemporânea do desenvolvimento da profissão e da teoria em arquitetura e em construção.

Neste primeiro número de 2015, a PARC apresenta artigos que compartilham as páginas da revista para demonstrar a importância da diversidade de contribuições na constituição de uma discussão coerente sobre a construção e o papel do processo de projeto em arquitetura.

No artigo "Target Value Design na gestão do processo de projeto por meio de simulação: difusão de conceitos e reflexões teóricas" os autores - Carolina A. Oliva, Reymard Savio S. de Melo e Ariovaldo Denis Granja, da Universidade Estadual de Campinas - identificam que, no atual contexto de incertezas que se observa no mercado imobiliário, uma estratégia é considerar o impacto dos custos do empreendimento no processo de projeto, fase anterior e, muitas vezes, dissociada da etapa de construção. Identificar parâmetros de valor para o cliente e para o usuário permite que o processo de projeto incorpore prioridades e eficiência no empreendimento, especialmente nos aspectos relacionados aos custos. Para demonstrar o impacto das decisões tomadas no processo projeto nos custos de empreendimento, os autores apresentam uma simulação conduzida em um jogo entre equipes constituídas por projetistas e construtores. Como conclusão, percebe-se que as restrições impostas pelos custos podem estimular soluções criativas, inovações e a maior integração entre equipes multidisciplinares.

O processo de projeto também é objeto de considerações que vão além da concepção do edifício no artigo "A avaliação da perspectiva dos arquitetos na redução de resíduos na etapa de projeto arquitetônico" dos autores Pedro Henrique Gonçalves, Ana Paula N. Ito e Débora Cristine G. de Carvalho da Universidade Estadual de Goiás. Discute-se como incorporar a questão da geração de resíduos e de sobejos na primeira fase de desenvolvimento da construção. $O$ fato de a metade dos resíduos sólidos urbanos no Brasil ser proveniente da atividade de construção civil, tanto na demolição como na construção, representa uma responsabilidade significativa para os profissionais envolvidos no setor de construção, onde o arquiteto também tem sua parcela de comprometimento. Assim, é inevitável que a antecipação da construção empreendida pelo projetista considere esta perspectiva, bem como o fato de a construção também consumir recursos naturais. A pesquisa empreendida pelos autores junto aos escritórios de arquitetura apresenta resultados que podem suscitar opiniões controversas, tanto sobre a indiferença de arquitetos sobre o assunto como uma sobrecarga de responsabilidades e expectativas junto ao processo de projeto.

$\mathrm{O}$ artigo "O tombamento de Iguape como patrimônio nacional: novas práticas e políticas de preservação" compõe de modo perspicaz o panorama geral apresentado neste número da Revista PARG ao apresentar critérios e iniciativas importantes de tombamento e preservação do patrimônio arquitetônico e urbanístico no exemplo de Iguape. As autoras - Flávia Brito do Nascimento e Simone Scifoni da Universidade de São Paulo - demonstram que, além das responsabilidades dos órgãos públicos nas esferas municipal, estadual e federal, a participação social e conscientização pública são fundamentais na manutenção a memória coletiva construída em torno da arquitetura e do urbanismo.

Tão visado nos resultados das discussões sobre construção, o processo de projeto é apresentado no artigo "Contribuição de Horst Rittel para a abordagem científica ao projecto no início da era computacional" a partir das contribuições dos métodos sistemáticos - ou sistémicos, nas palavras da autora - estruturados a partir dos anos 1960 no mundo todo. O contexto em que a escola HfG-Ulm se desenvolveu entre 1953 e 1968 na Alemanha, como apresentado no artigo pela autora Isabela Clara Neves da Universidade de Lisboa, é fascinante e estimulou a aplicação dos métodos científicos nos primeiros experimentos computacionais voltados à solução de projetos em arquitetura e engenharia. $\mathrm{O}$ trabalho de Horst Rittel é apresentado em seus primeiros momentos $\mathrm{e}$ anterior às suas contribuições mais conhecidas - como o IBIS (IssueBased Information System) e a definição dos "wicked 
problems", também abordados no artigo - e associado às aplicações de métodos de investigação operacional, teoria da decisão matemática, teoria dos jogos, análise de sistemas e técnicas de planejamento. O impacto da formação em matemática de Horst Rittel na organização do processo de projeto faz lembrar do seu contemporâneo Christopher Alexander cuja carreira, no mesmo momento histórico e também matemático, toma rumos semelhantes em Harvard. Na conclusão do artigo, os autores comprovam que a contribuição de Horst Rittel foi a de um pensamento de padrões que substituiu um pensamento de objetos, "e a produção de padrões substituiu a produção de objectos". Neste artigo os autores oferecem aos leitores da Revista PARC o privilégio de assistir os primeiros momentos do desenvolvimento dos métodos de projeto no trabalho inicial de um teórico importante, mas pouco conhecido, que foi Horst Rittel.
Finalmente, o artigo "Cota de solidariedade: comparado políticas entre cidades Norte Americanas e São Paulo" dos autores Ana Beatriz P.P. da Costa, Giovanna Helena B. de Albuquerque e Luiz Filipe Rampazio, da Universidade de São Paulo, na sessão "Nova Geração" da revista PARC apresenta as características da cota de solidariedade - em que uma parte dos empreendimentos imobiliários é destinada à habitação social - e sua implementação no Brasil e nos Estados Unidos. A iniciativa se apresenta como uma estratégia de planejamento urbanístico ao permitir aos moradores e trabalhadores de baixa renda acesso às regiões estruturadas das cidades. Enquanto os artigos anteriores destacam as novas responsabilidades do processo de projeto junto ao empreendimento de construção, a nova geração de autores apresenta a possibilidade de comprometimento do mercado imobiliário com proporcionar comunidades heterogêneas, abertas e inclusivas.

\section{Agradecimentos}

Agradecemos aos avaliadores pelo pronto retorno, tempo despendido e valiosas considerações tecidas sobre os artigos submetidos.

\section{Referências}

ADDIS, Bill. Edificação: 3000 anos de projeto, engenharia e construção. 1. ed. Porto Alegre: Bookman, 2009.

BROADBENT, Geoffrey. Diseño arquitectónico. 2. ed. ed. Barcelona: Gustavo Gili, 1982.

COSGROVE, Denis. Ptolemy and Vitruvius: spatial representation in the sixteenth-century texts and commentaries. In: PICON, Antoine; PONTE, Alessandra (Ed). Architecture and the sciences: exchanging metaphors. Princeton papers on architecture. 1. ed. New York: Princeton Architectural Press, 2003. p. 20-51.

HEARN, Fil. Ideas que han configurado edificios. Barcelona: Gustavo Gili, 2006.

MAINSTONE, Rowland J. Brunelleschi's Dome of S. Maria del Fiore and some Related Structures. Transactions of the Newcomen Society, v. 42, n. 1, p. 107-126, 1 jan. 1969.

\section{${ }^{1}$ Daniel de Carvalho Moreira}

Arquiteto. Doutor em Engenharia Civil (UNICAMP). Professor Doutor II (UNICAMP). Endereço postal: Av. Albert Einstein, 951, Campinas, SP, Brasil, CEP 13.083-852.

\section{${ }^{2}$ Regina Coeli Ruschel}

Engenheira Civil. Doutor em Engenharia Elétrica e da Computação (UNICAMP). Livre Docente em Projeto Auxiliado por Computador (UNICAMP). Endereço postal: Av. Albert Einstein, 951, Campinas, SP, Brasil, CEP 13.083-852 